health of the population may be improved. Without this independence such issues may be lost in the present political and economic climate of the NHS and with the strong financial orientation of managers. ${ }^{7}$

The old style reports of medical officers of health were criticised for simply rehashing routine statistics rather than covering fresh ground and showing improvements in health. They became "stereotyped and stale . . . an annual chore of questionable value." If directors of public health are to avoid this fate for their annual reports they need to evaluate their reports' impact against widely agreed national and local criteria. This does not mean that the content and format of reports should be rigidly dictated but simply that there should be agreement about their purpose and objectives. The tension between independence and corporate ownership must either be resolved or be used constructively to achieve debate for the overall benefit of the public health.

Another review of the public health function within the NHS has been announced ${ }^{89}$; we hope that this review will consider the function of annual reports and how to evaluate their effectiveness; the issue of the independence of reports must also be addressed. Public health medicine has long considered itself to have a legitimate role in measuring clinical outcomes and the effectiveness of health care; it should not forget to look in its own back yard.

IAN S WATT

Senior registrar in public health medicine

SUE L IBBOTSON

Senior registrar in public health medicine

CAROL NICHOLSON

Epidemiologist

East Riding Health Authority,

Hull HU2 8TD

1 Department of Health and Social Services. Public health in England: the report of the committee of inquiry into the future development of the public health function. London: HMSO, 1988. (Cmnd 289; Acheson report.)

2 Pencheon D, Gray, eds. Health measurement toolbox. 3rd ed. London: Faculty of Public Health Medicine, 1991.

Department of Health. Annual repors on the health of the population: content review. London: DoH, 1990. (EL(90)P/8.1.)

4 Gair R, Li Chee Lan L, McKee M, Parikh C, Weinberg J. Criteria for audit of annual reports on the public health: do they exist? I Public Health Med 1992;14:169-72.

5 Freemantle N, Watt IS, Mason J. Developments in the purchasing process in the NHS: towards an explicit politics of rationing. Public Administration (in press).

explicit politics of rationing. Public Administration (in press).
6 What's new in public health? [Editorial.] Lancet 1991;337:1381-3.

7 Pollitt C, Harrison S, Hunter DJ, Marnoch G. General management in the NHS: the initial impact. Pollitt C, Harrison S, Hunter DJ, Marnoc
Public Administration 1991;69:61-83.

8 Department of Health. On the state of the public health: the annual repont of the chief medical officer of the Department of Health for the year 1991. London: HMSO, 1992.

9 Department of Health. Review of public health guidance to the NHS needed says Brian Mawhinney. London: DoH, 1993. (Press release No H93/509.)

\title{
How should new treatments for benign prostatic hyperplasia be assessed?
}

\author{
Symptomatic measurements are not enough
}

Benign prostatic hyperplasia may present in several ways. ${ }^{1}$ Some patients seek treatment for clearly obstructive symptoms, others for irritative symptoms (such as frequency, nocturia, and urgency) resulting from secondary bladder instability. In some, chronic retention develops insidiously and if associated with high bladder pressure may lead to hydronephrosis and obstructive uraemia. Acute retention commonly presents in men not previously worried by urinary symptoms.

Measuring the outcome of treatment for benign prostatic hyperplasia has not previously been of great interest. Indeed, it must be admitted that urologists have been cavalier in assessing the benefits of transurethral prostatectomy. A quick follow up interview, to see whether the patient is happy with the symptomatic outcome of his treatment, is the most that is usually done, and some urologists even question the need for routine postoperative follow up. For a man who has had retention, to be able to pass urine spontaneously is a successful outcome, easy to assess. In most cases the preoperative problem is one of troublesome symptoms rather than life threatening morbidity; if after surgery the patient is happy perhaps all is well. Unfortunately, a satisfactory outcome from transurethral prostatectomy is not invariable, a reflection more of difficulties in selection for treatment than of inadequacies of the treatment itself. ${ }^{2}$

Things are no longer so simple. Many new treatments have now been proposed for benign prostatic hyperplasia including drugs, prostatic hyperthermia, stents, balloon dilatation, and laser prostatectomy. Elsewhere in this journal Bdesha and colleagues report a trial of transurethral microwave hyperthermia in which actively treated patients were compared with a control group who received sham treatment (p 1293). ${ }^{3}$ Active treatment produced a significant symptomatic improvement but only a small and non-significant increase in flow rate, which was the measure of obstruction used. Although these new treatments probably work, they are considerably less effective than standard surgical treatment. To assess them we need measurements that can show not only that they work but also how they compare with the alternatives.

The symptoms produced by benign prostatic hyperplasia result from bladder outflow obstruction. ${ }^{2}$ The relief of obstruction is the aim of treatment, and effective treatment should produce objective improvement in measures of obstruction. The hallmark of obstruction is a reduced urine flow associated with an abnormally high voiding pressure. Although residual urine is not an accurate indicator of obstruction, a high residual volume after voiding, which improves after effective treatment, is an additional feature of the condition. In practice, measurement of voiding pressure is invasive and inconvenient, and, although rigorous assessment would demand its use, urine flow measurements alone are used in routine assessment and are the commonest objective measurement in trials of new treatments. Non-invasive measurement of residual urine volume by ultrasonography is frequently added. With the possible exception of prostatic stents, ${ }^{4}$ no method of treatment approaches transurethral prostatectomy (or open surgery) in improving these variables.

Patients, however, seek treatment not for abstract urodynamic concepts but for symptoms. Indeed, all urologists occasionally see the unhappy man still rising several times a night after his transurethral prostatectomy who fails to be impressed by his improved flow rate. Many men with prostatic symptoms are reluctant to submit themselves to surgery-hence the place for alternative treatments. Although the urologist would want objective evidence of the relief of obstruction, symptomatic improvement must also be documented. In most studies a system of symptom scoring is 
used. ${ }^{5}$ This aims to quantify symptoms reproducibly; some scores include a quality of life or "bothersome" element.

Prostatic obstruction is partly dynamic, resulting from the smooth muscle component of the prostatic stroma. This is the therapeutic basis for treatment with $\alpha$ adrenergic blocking drugs $^{6}$ but also leads to the substantial placebo effect which is such a feature in clinical trials of treatment for benign prostatic hyperplasia. ${ }^{7}$ Patients in the control groups experience an improvement not only in symptoms but also in objective measurements such as flow rates. Although validating new treatments by controlled studies is relatively easy with medical treatment, true double blind trials are difficult, if not impossible, with mechanical or operative manipulations. Indeed, the sham treatment used by Bdesha and colleagues may not be entirely blind but is probably the best that can be achieved.

What we can tell our patients is that no treatment for benign prostatic hyperplasia is as good as surgery. We can reassure them that despite its long history transurethral prostatectomy fulfils the definition of a minimally invasive operation. It is not without its hazards, however, and perhaps the problem caused by the disease in many men does not merit surgery.
After all, a hip replacement operation is not the only way of managing arthritis and angina does not always warrant coronary artery surgery. What we must not do is persuade ourselves and our patients that an alternative is effective until it has been tested. Unfortunately, the rigorous standards that are necessary for evaluating drugs are not always adhered to with technological developments. Bdesha and his colleagues are to be congratulated for their attempt to do so.

DAVID KIRK

Western Infirmary, Consultant urologist

Glasgow G11 6NT

1 Kirby R, Christmas T. Benign prostatic hyperplasia. London: Gower Medical, 1993.

2 Neal DE, Ramsden PD, Sharples L, Smith A, Powell PH, Styles RA. Outcome of prostatectomy. BMF 1989;299:762-7.

3 Bdesha AS, Bunce CJ, Kelleher JP, Snell ME, Vukusic J, Witherow RO'N. Transurethra microwave treatment for benign prostatic hypertrophy: a randomised controlled clinical trial. $B M F$ 1993;306:1293-6.

4 Chapple CR, Milroy EJG, Rickards D. Permanently implanted urethral stent for prostatic obstruction in the unfit patient. Br $\mathcal{G}$ Urol 1990;66:58-65.

5 Boyarsky S, Jones G, Paulson DF, Front CR. A new look at bladder neck obstruction by the Food and Drug Administration regulators: guidelines for investigation of benign prostatic hypertrophy Transactions of American Association of Genito-Urinary Surgeons 1977;68:29-32.

6 Chapple CR. Medical treatment of benign prostatic hyperplasia. BMf 1992;304:1198-9.

7 Lloyd SN, Buckley JF, Chilton CP, Ibrahim I, Kaisary AV, Kirk D. Terazosin in the treatment of benign prostatic hyperplasia: a multicentre, placebo-controlled trial. Br $\mathcal{J}$ Urol 1991;70 (suppl 1):17-21.

\section{Nicotine patches in general practice}

\section{They work about as well as nicotine chewing gum in motivated patients}

Transdermal nicotine was shown to mitigate craving and withdrawal symptoms in 1985 and, when combined with behavioural therapy, to increase abstinence rates in smokers attending a cessation centre. ${ }^{1-3}$ Its use by general practitioners in Switzerland was described by Abelin et al in 1989: they showed that middle aged dependent smokers, who were seen monthly over three months, were helped more by transdermal nicotine than by placebo patches. Abstinence was increased and craving reduced, but $5 \%$ were unable to tolerate the cutaneous adverse affects of erythema, oedema, and itching. ${ }^{4}$ Motivated, middle aged, "healthy" smokers ( $\geqslant 20 /$ day) recruited to the Mayo Clinic by newspaper advertisements were treated with a 24 hour transdermal nicotine patch or placebo for six weeks, during which time they were seen weekly for 30 minutes by a nurse. At one year $23 \%$ of the group treated with transdermal nicotine had given up smoking compared with none who received placebo. ${ }^{5}$

In another study a 16 hour nicotine patch was compared with a 24 hour patch in volunteer smokers over a month: when compared with placebo both patches trebled the rate of stopping at one month and six months and reduced withdrawal symptoms, but no difference was found between the two treatments. ${ }^{6}$ In a Danish study a 16 hour transdermal nicotine patch given for 16 weeks with a moderate amount of doctors' advice and support to smokers ( $\geqslant 20 /$ day) recruited by newspaper advertisements was superior to placebo at one year ( $11 \%$ v $2 \%$ stopped smoking) ${ }^{7}$ and still seemed better than placebo at two years. ${ }^{8}$ A literature review up to 1992 concluded that transdermal nicotine worked in motivated, middle aged smokers of 20 or more cigarettes a day when used in specialised smoking cessation settings but emphasised the need to provide adequate support and counselling if success rates as good as or better than the $26 \%$ reported by the Transdermal Nicotine Study Group were to be achieved. ${ }^{9} 10$

Because it is unlikely that the limited resources of Britain's NHS will ever permit such a high level of attention and support two papers in this week's journal make reassuring reading (pp 1304, 1308). ${ }^{11} 12$ Both used intervention schemes that could easily be applied widely in general practice. The populations studied were from 19 practices in Oxfordshire ${ }^{11}$ and 30 practices around Britain ${ }^{12}$ and were selected for dependence on cigarettes and for motivation. Treatment lasted between 12 and 18 weeks. Practice nurses provided advice and support in Oxfordshire while in the other study this was provided by the general practitioner or nurse or both. In the Oxfordshire study a 24 hour patch resulted in continuous abstinence for 11 weeks in $14 \%$ of subjects compared with $9 \%$ treated with placebo $(p<0.001)$. In the nationwide study a 16 hour patch resulted in $9 \%$ not smoking for 12 months compared with $5 \%$ with placebo $(p<0.001)$.

Craving and mood disturbance were helped by transdermal nicotine. Erythema and itching were more common with transdermal nicotine than placebo, with $2-10 \%$ of patients stopping transdermal nicotine because of these adverse affects. Sleep disturbance was more common with 24 hour transdermal nicotine than placebo, but in neither study were headache or gastrointestinal symptoms more common with transdermal nicotine. Increasing the dose at one week for those having particular difficulties giving up smoking increased the rate of stopping at three weeks, and there was no advantage in gradual as opposed to abrupt withdrawal of transdermal nicotine after 18 weeks' treatment. ${ }^{12}$

For hospital patients with smoking related diseases moderate levels of advice and support resulted in $20 \%$ sustained success at one year, with or without nicotine chewing gum, ${ }^{13}$ which was much better than the success rates obtained in studies that provided minimal amounts of advice and support in similar populations. ${ }^{14}{ }^{15}$ Transdermal nicotine combined with advice and support has been compared with placebo patches in 234 hospital patients; at six months the rates of stopping were $25 \%$ and $18 \%$ respectively $(p>0.05) .^{16}$

The evidence indicates that transdermal nicotine is an effective adjunct to simple advice and support given to motivated smokers in the setting of general practice or in 